\title{
Listen to Your Body
}

\author{
Viviana Siddhi* \\ Slovenian-Born Artist, NGO Mandala Transformation, USA
}

*Corresponding author: Viviana Siddhi, Slovenian-Born Artist with American Citizenship, NGO Mandala Transformation, Inc., California, USA.

Received Date: January 22, 2020

Published Date: February 06, 2020

\section{Short Communication}

"Kawakami became so secure while doing this type of breathing, and felt so profoundly pacified during it, he came to see it as a state of enlightment. "I am able to attain a spiritual state of perfect stillness," he told me, "and while doing so, I can control my five senses, so I don't feel anything" [1].

If your body is telling you that you are tired or hungry or that a muscle is sore, it is straightforward to know how to take case of that need. Sometimes, sensations arise, and we have no idea why we are feeling what we're feeling.

If you are like most of us and have spent much of your life ignoring the sensations of your body, exercises for "Body Awareness" can be more challenging. I assure you that as you tune into your body's language more frequently, it will become much simpler to feel your sensations and notice the quality of those sensations in more detail.

If you have found it difficult to sense what is happening within your body, don't worry. It can take some time to develop the ability to feel inside yourself again. I promise that it is possible and that it's well worth it! It can sometimes be helpful to touch the area of your body that you're focusing on, let's say your belly, with your hand. Some people feel sensation, and other people can visualize, or "see", sensation inside of their bodies.

Bringing sensory awareness back to our bodies is the first step to healing pain and shame that we have experienced. Our entire bodies deserve our attention and our care. Once we learned to sense what is going on inside our bodies, we're beginning to speak the basic language of the body. Many sensations are related to emotional experiences. The sensation is physical, but the meaning of the sensation is emotional. Learning how to feel what the sensation means to us allows us a much deeper understanding of our body language.

Simple exercise for "Body feelings":

A. Relax, lie down and take time for yourself.
B. Focus on the area that you would like to improve or heal. For example: kidney, liver, eyes, etc.

C. Ask that part of the body what it needs.

D. The message will arise out of the silence.

E. Purify your body, mind and spirit.

How we think and feel, our responsiveness to our bodies and behavior that we choose absolutely to affect our health. Ignoring the obvious cues from your body that something is wrong can manifest in more serious illness. We can influence pain and illness with our thoughts and behaviors does not mean that we cause all our pain and illness. Blaming illness on the person suffering is never helpful. It is bringing additional stress. We should listen to our bodies and discern the meaning of pain and illness. We must not get bogged down in the cycle of self-blame or shame about having the illness.

"Reducing your stress can be done with a simple belly breathing exercise. Any form of meditation or prayer, including the moving meditations of yoga, tai chi, or qigong, can help. Gentle exercise walking, for example - especially if it is outside in nature, is very healing for the adrenals. Getting adequate, good-quality sleep is absolutely essential". [2]

Every living being longs always to be happy, untainted by sorrow, and everyone has the greatest love for himself, which is solely because happiness is his real nature. Hence, in order to realize that inherent and untainted happiness, it is essential that he should know himself. Unfortunately, not everybody really wants to know reality. There's also a part of everyone's nature that's comfortable with the status quo or illusions and they don't like changes. Many are afraid about being right or wrong instead to focus on solutions.

"Faith in the rightness of what you're doing is the certainty of your own success. Faith is bolstered by energy (vinya) and enthusiasm in the original sense of the word, which is to be inspired or possessed (entheos) a god." The person who has control over 
himself attains verily success through faith, none other can succeed. Therefore, with faith, the Yoga should be practiced with care and perseverance.

Clear intention and constant mindfulness (smirti) of what you're doing and why, regarding both short-term and long-term goals and in the subtle adjustments of everyday practice.

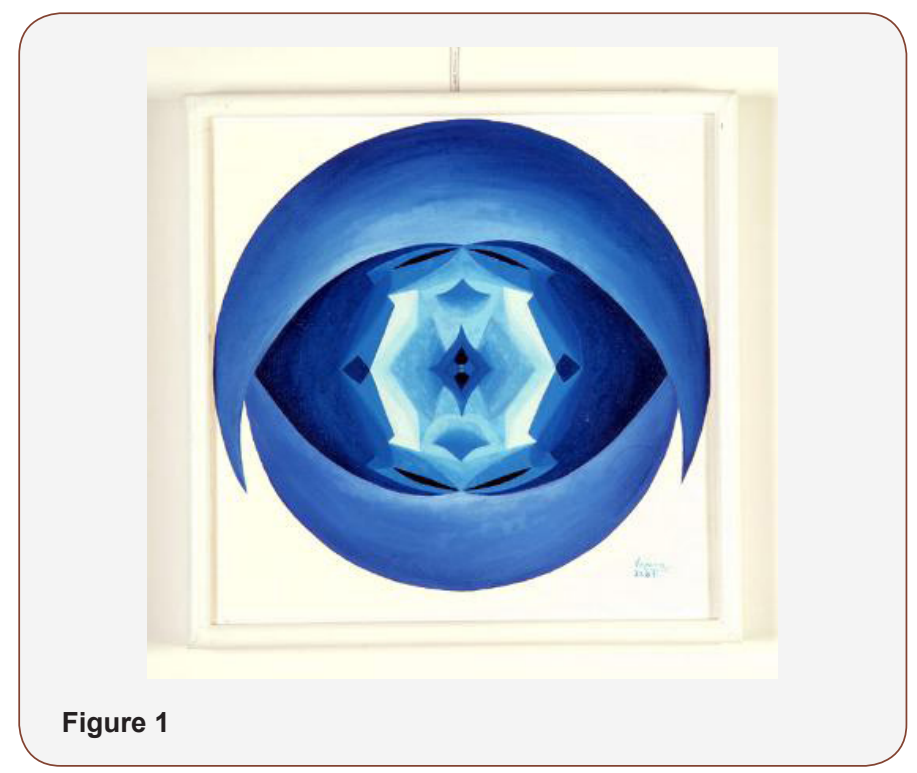

Contentment (samtosha) which accommodates both success and failure with good humor and grace, and self-acceptance; at the same time, the willingness to take risks and embrace uncertainty. "As long as one is not satisfied in the self, he will be subjected to sorrow. With the rise of contentment, the purity of one's heart blooms. The contented man who possesses nothing owns the world.

Careful discrimination (viveka) between what's important to your practice and what's not, and the willingness to surrender the latter.

Open-minded study (svadhyaya) of traditional and contemporary guides to breathing and yoga and associating with and contemplating on what Patanjali calls the vita-ragas, the beings who have conquered attachment. "By listening to instructions, by contemplation and by being in the company of a calm and sureminded preceptor, doubts can be removed" [3].

\section{Install Art}

With a simple thought "I can", you'll achieve self-confidence. It gives you strength and peace by washing away doubt and allowing you to trust yourself. "I can" is a statement of confidence in life itself. "I can" is fuel for the soul that sparks the desire to work out. "I can" dissipates the fear of failure. A positive image of being strong brings resiliency and yourself, in your own inner power, your ability to function in the world, and your connection to the world of spirit. Self-confidence brings you well-being.

Stop over-thinking and do something good for yourself.

"Goals related to your inner soul or spirit are usually less measurable. Becoming a more loving person is subjective. It's tough to chart whether one has been successful at changing negative thoughts into positive ones. Often knowing a Fit soul goal has been fulfilled only happens after the change has occurred. Staying on track with transformations of the soul are most easily seen by reflecting on our day-to-day actions". [4]

Each day remind yourself to live in a positive way with positive thoughts, words and actions.

"Yoga teaches that you need to attract the energy you put out, whether that's anger, negativity, and violence, or generosity, compassion, and love. That's karma again." [5].

We have to consciously choose the path of love, love of God, love of community, love of ourselves and love will come back to us. Do not harm yourself and others. When we do yoga - go slowly, respect your body's limits, and listen to its innate wisdom. The more you do yoga, the more you'll have access to that intuitive sense of what's good for you and what isn't. My body had been speaking to me, but I'd chosen to ignore what it was saying. We must reach the state of peace and then it's easy to listen to body's language. We must practice with awareness.

"Here he is concentrated wholly on a single point or on a task in which he is completely engrossed. The mind must be stilled in order to achieve this state of complete absorption. The mind is an instrument which classifies, judges and co-ordinates the impressions from the outside world and those that arise within oneself.

Mind is the product of thoughts which are difficult to restrain for they are subtle and fickle. A thought which is well guarded by a controlled mind brings happiness. To get the best out of an instrument, one must know how it works. The mind is the instrument for thinking and it is therefore necessary to consider how it functions. Mental states are classified in fine groups." [6]

Whenever possible, think joyous, happy, and harmonious thoughts. Yogis believe that these bring well-being to mind and body. Positive affirmations are bringing positive attitude.

"The law of action and reaction teaches that doing good deeds attracts goodness to us and, conversely, that doing bad deeds attracts ill. This is true of thoughts as well as deeds. The reaction provoked by a thought will be of the same nature and quality as the thought itself, so a negative thought attracts a negative reaction and a positive thought a positive one. Today, we tend to believe that others are responsible for what happens to us, especially for the more challenging episodes. We are quick to blame parents, teachers, or society at large for our ills. We fail to realize that our negative thoughts and emotions - fear of failure, resentment, anger, self-hatred - generate powerful, negative vibrations. These attract negative energy that influences events, the people we meet, and even the diseases we get. For example, dwelling on unhappy memories and worrying that painful things will happen again sets up a vibration of fear, which attracts fear and pain. This is the law of karma". [7]

Once, we realize that we can step out of this karmic circle, we are free. In a good way we can consciously create our life and destiny without negative (evil) intentions. Everything, what we do we love to do with unconditional love. We are finally happy, healthy and in peace. 
The relaxation and breathing exercises are important elements. The stresses and strains of modern living can result in bunched - up, tense muscle which in turn lead to headaches, back strain and injuries. Make sure to incorporate exercises, as they will help relieve tension, restore flagging energy levels and, just as crucially, induce a tranquil state of mind.

It is now widely accepted that mental or emotional stress often transforms itself into muscle tension. And it does seem that the back is one of the main places where tension is stored. The neck and shoulders are often one mass of knotty tension. Muscle spasm due to unexpressed tension and worries can also be in other parts of the back.

"Strength is a key component of healthy physical performance; strong muscles help you move easily and enjoy life. And unlike many other things in life, muscles respond to stress in a positive way. They get stronger. Strength training is a safe and effective way to improve muscle capabilities and to increase healthy physical performance. Good programs do much more than add bulk - they help to sculpt and stabilize the body. You can gain strength and muscle size throughout your life. It is never too late to start". [8]

\section{Acknowledgement}

None.

\section{Conflict of Interest}

Author declare no conflict of interest.

\section{References}

1. Jill Blake (2019) Energy Medicine. HarperCollins Publishers, New York, pp. 159.

2. Rachel Carlton Abrams (2016) Body Wise. Rodale, New York, p. 53.

3. Richard Rosen (2002) The Yoga of Breath Shambala. Boston, USA, pp. 320.

4. Brant Secunda, Mark Allen (2008) Fit Soul Fit Body. Ben Bella Books, Dallas, Texas, p. 90.

5. Timothy McCall (2007) Yoga as Medicine. Bantam Dell, New York, USA, p. 86.

6. BKS Iyengar (1979) Light on Yoga. Schocken Books, New York, USA, p. 48.

7. Sivananda Yoga Vedanta Center (2010) Yoga. DK Publishing, New York, USA, p. 206.

8. Marilyn Moffat, Carole B Lewis (2006) Age Defying Fitness. Peachtree Publishers, USA. 